\section{A Very Rare Case, Coexistence of Invasive Thyroid Papillary Carcinoma and Parathyroid Carcinoma in Hypercalcemic 29 Year Old Woman Who Is Treated For Urolithiasis}

\author{
Dilara Demir ${ }^{1 *}$, Özgen Çeler ${ }^{2}$, Melahat Arslan ${ }^{3}$ and Zeynep \\ Hulya Durmaz ${ }^{4}$
}

${ }^{1}$ Department of Internal Medicine, Amasya University Research Hospital, Amasya, Turkey

${ }^{2}$ Department of Endochrinology and Metabolism, Amasya University Research Hospital, Amasya , Turkey

${ }^{3}$ Department of Nuclear Medicine, Amasya University Research Hospital, Amasya, Turkey

${ }^{4}$ Department of Biochemistry, Amasya University Research Hospital, Amasya, Turkey

\begin{abstract}
\section{Introduction and purpose}

Primer hyperparathyroidism is the most common cause of hypercalcemia in patients who referred to the policlinics. Thyroid Cancer (ca) is observed nearly $1 \%$ in all cancers. It has been increasing most common type and consisting about $80 \%$ of the thyroid cancers. Coexistence of nonmeduller thyroid ca and primer hyperparathyroidism is very rare situation.

\section{Case report}

A 29 year old woman, she was treating for urolithiazis for four years. Her Ca is found $14.50 \mathrm{mg} / \mathrm{dl}$. Parathyroid Hormone (PTH) level is found $851.5 \mathrm{pg} / \mathrm{ml}$. Thyroid usg ve and Tc-99m MIBI parathyroid scintigrafia was performed. She was referred to a tertiary center for the operation. Pathology results were reported as papillary thyroid Carcinoma (ca) and parathyroid carcinoma. Tumor was infiltrated to surrounding muscles tissue and to the front wall of esophagus.

\section{Conclusion}

In this article, coexistence of thyroid papillary ca and parathyroid carcinoma in hypercalcemic 29 year old woman who is treated for urolithiasis is presented.
\end{abstract}

*Corresponding author: Dilara Demir, Department of Internal Medicine, Amasya University Research Hospital, Amasya, Turkey, Tel: +90 35821840 00; E-mail: adilarabay@gmail.com

Citation: Demir D, Çeler O, Arslan M, Durmaz H (2017) A Very Rare Case, Coexistence of Invasive Thyroid Papillary Carcinoma and Parathyroid Carcinoma in Hypercalcemic 29 Year Old Woman Who Is Treated For Urolithiasis. J Diabetes Metab Disord 4: 020.

Received: May 16, 2017; Accepted: July 20, 2017; Published: August 03, 2017

Copyright: (C) 2017 Demir D, et al., This is an open-access article distributed under the terms of the Creative Commons Attribution License, which permits unrestricted use, distribution, and reproduction in any medium, provided the original author and source are credited.
In patients who admitted to policlinics with non specific complaints, weakness, fatigue, nausea working serum electrolytes is very important. Ca must be added to these parameters. In such patients Coexistence of parathyroid carcinoma and thyroid malignancies should be kept in mind.

Keywords: Hypercalcemia; Parathyroid carcinoma; Thyroid papillary carcinoma

\section{Introduction}

Primer hyperparathyroidism is the most common cause of hypercalcemia in patients who referred to the policlinics [1]. Thyroid Cancer (ca) is observed nearly $\% 1$ in all cancers. It has been increasing most common type and consisting about $80 \%$ of the thyroid cancers. Papillary and follicular cancer's incidence increases with age median age is 45-50 years [2]. Coexistence of nonmeduller thyroid ca and primer hyperparathyroidism is very rare situation. Coincidence of nonmeduller thyroid ca and primer hyperparathyroidism is reported as $\% 2-13$ [3].

We present here a 29-year-old woman who had papillary thyroid carcinoma and parathyroid carcinoma concurrent.

\section{Case presentation}

A 29 year old woman with a 2-month history of loss of appetite, weight loss, fatigue, tiring easily that affect her daily work, 5 days history of nausea and vomiting presented to our internal medicine clinic in October 2015. She was treating for urolithiazis for four years and referred to the emergency clinic for nausea and vomiting yesterday. She has no other familial disorders. Physical examination was normal. Her biochemical parameters revealed very high Calcium (Ca) levels. Her $\mathrm{Ca}$ is found $14.50 \mathrm{mg} / \mathrm{dl}(8,6-10 \mathrm{mg} / \mathrm{dl})$, Parathyroid Hormone (PTH) level is found $851.5 \mathrm{pg} / \mathrm{ml}$ ( 11,1-79,5 pg/ml), 25-Hidroksi Vitamin D: $20 \mathrm{ng} / \mathrm{ml}$. To investigate Primer hyperparathyroidism thyroid usg ve and Tc-99m MIBI parathyroid scintigrafia was performed.

In Thyroid usg: Right lobe of the thyroid anterior posterior diameter is 23 millimeters ( $\mathrm{mm}$ ) measured. It was increased. Left lobe of the thyroid Antero Posterior diameter (AP) is $15 \mathrm{~mm}$, isthmus AP diameter is $2 \mathrm{~mm}$ measured. It was in physiological levels. In right lobe anterior segment $16 \times 10 \mathrm{~mm}$, properly limited, including internal punctuate calcifications hypo echoic, hyper vascular nodule was observed. Also there is a $21 \times 28 \mathrm{~mm}$ lobulated, containing internal echogenic septation solid nodules starting from central part of the right lobe ongoing up to posterior were observed. In both lobes colloidal cystic nodules were observed in mill metric scale.

In thyroid gland left lobule early images revealed that activity distribution is homogeneous and in normal range. The upper lobe of right middle lobe's activity uptake was increased. In late images when washout was defined from left lobe and lower pole of right lobe in the right lobe uptake persevered. It evaluated atopic for parathyroid adenoma by reason of settlement by scintigraphy. It was also reported to be secondary to thyroid pathology.

The patient was hydrated. Ca level was found $12.40 \mathrm{mg} / \mathrm{dl}$ and $13.20 \mathrm{mg} / \mathrm{dl}$. Despite hydration her Ca level did not fall more. She was 


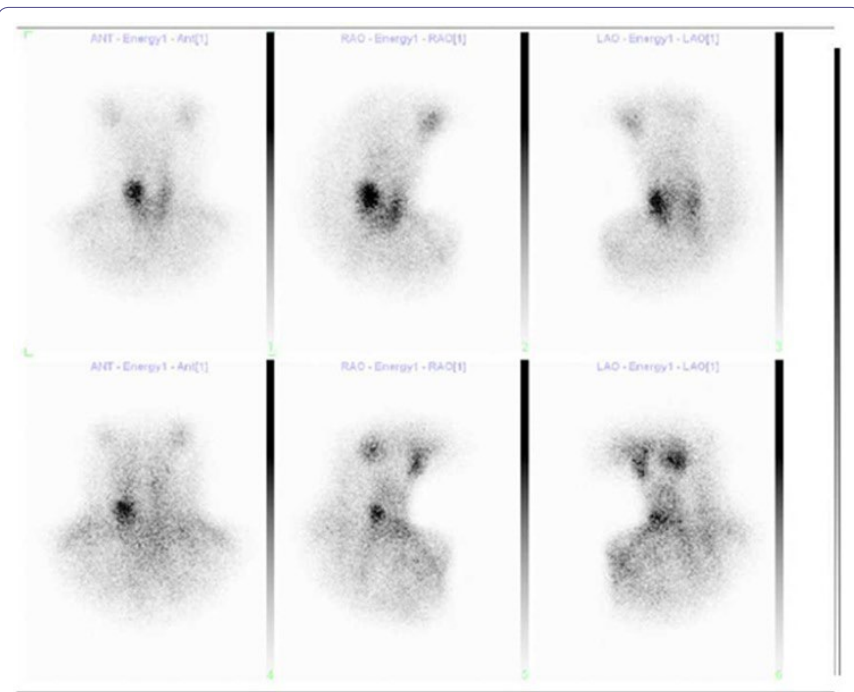

Figure 1: Scintigraphy of Thyroid Gland.

referred to a tertiary center for the operation. In the tertiary center after regulated calcium levels total thyroid ectomy and excision of the parathyroid carcinoma was performed. Pathology results were reported as papillary thyroid carcinoma and parathyroid carcinoma. Tumor was infiltrated to surrounding muscles tissue and to the front wall of esophagus.

In follow up her parathyroid hormone was: $0.9 \mathrm{pg} / \mathrm{ml}$ and Ca was $9.7 \mathrm{mg} / \mathrm{dl}$.

\section{Discussion}

We encounter primary hyperparathyroidism as a third most common endocrine disorder [4]. Primer hyperparathyroidism caused by parathyroid adenoma, gland hyperplasia, parathyroid carcinoma, is the most common cause of hypercalcemia in patients who appeal to the hospital. Its incidence increases in seventh decade in both genders. Many years ago primer hyperparathyroidism frequently was presented with renal stones, osteoporosis, bone pain, weight loss, fatigue, nausea, vomiting, and depression. But after studying Ca in rutin biochemistry tests, it is presenting as asymptomatic situation with high Ca levels [5].

Most common thyroid malignancy is papillary thyroid carcinoma and the second one is follicular thyroid ca which is caused by follicle cells. It is among the most curable cancers. Despite thyroid nodules, carcinomas are seen very rare less than 1 percent of all cancers. It is seen more frequent in women than men. On cogenesis and irradiation have important role in its pathogenesis [2].

Papillary thyroid ca's incidence has increased in recent years [6]. Also it's the most common cancer in women under 35 years of age. It's incidence increase with age [7].

Parathyroid cancer is very rare malignancy. It's about less than $1 \%$ of all cases. Risk factors are genetic disorders, neck irradiation and often sporadic [8]. Although often seen with parathyroid and thyroid disease together, coexistence of parathyroid carcinoma and thyroid papillary ca is very rare [9]. Our case is among the rare cases in this regard. It draws attention that how this patient refers to policlinics with obscured symptoms.

Burmeister LA and friends studied 824 patients who underwent operation and they found twenty-two of them had thyroid carcinoma.
Twenty-one had papillary ca and one had follicular ca [10]. Zhao $\mathrm{H}$ and friends presented a 63-year old man who had bilateral papillary thyroid carcinoma concurrent with a parathyroid adenoma [11].

Ming-Che Chang and friends described a case report of a 49 year old woman who has concomittant parathyroid adenoma and papillary thyroid carcinoma who referred to hospital with anterior chest pain and biochemical parameters were revealed high serum Ca levels [12].

Bora Boston and friends present young female patient who examined with dyspepsia, loss of appetite, myalgia, arthralgia, fatigue, and pathologic fractures among six years but did not had any diagnosis. They suggest that it is important to search full biochemical parameters in patients who referred to policlinics with non specific complaints as dyspepsia, loss of appetite, myalgia, arthralgia, fatigue [13].

Hamid Javadi and friends described a 23-year-old man who had papillary thyroid carcinoma and parathyroid adenoma presented to nuclear medicine department for $99 \mathrm{mTc}$ thyroid scan [14].

Melanie Goldfarb and friends presented a 59 year old man with synchronous parathyroid carcinoma, parathyroid adenoma and papillary thyroid carcinoma. He had history of hypercalcemia 8 years ago. He refused treatment and after several years presented with pathologic fractures [15].

Today severe hyperparathyroidism accompanied by renal stones and metabolic bone diseases is seen very rare [4]. Despite primer hyperparathyroidism is more common in postmenopausal women our case is 29 years old. This should make us think to severe hyperparathyroidism may be in young individuals. In patients who admitted to policlinics with nonspecific complaints, weakness, fatigue, nausea working serum electrolytes is very important. Ca must be added to these parameters. In such patients Coexistence of parathyroid carcinoma and thyroid malignancies should be kept in mind.

\section{References}

1. Carlson D (2010) Parathyroid Pathology Hyperparathyroidism and Parathyroid Tumors. Arch Pathol Lab Med 134: 1639-1644.

2. Schlumberger MJ (1998) Papillary and Follicular Thyroid Carcinoma. N Engl J Med 338: 297-306.

3. Lehwald N, Cupisti K, Krausch M, Ahrazoglu M, Raffel A, et al. (2013) Coincidence of primary hyperparathyroidism and nonmedullary thyroid carcinoma. Horm Metab Res 45: 660-663.

4. Fraser WD (2009) Hyperparathyroidism. Lancet 374: 145-58.

5. Marcocci C, Cetani F (2011) Primary Hyperparathyroidism. N Engl J Med 365: 2389-2397.

6. Lei J, Zhong J, Jiang K, Li Z, Gong R, et al. (2017) Skip lateral lymph node metastasis leaping over the central neck compartment in papillary thyroid carcinoma. Oncotarget 8: 27022-27033.

7. Cheng Q, Li X, Acharya CR, Hyslop T, Sosa JA, et al. (2017) A novel integrative risk index of papillary thyroid cancer progression combining genomic alterations and clinical factors. Oncotarget 8: 16690-16703.

8. Sâgovâ I, Stancrk M, Kentos P, Pavai D, Kantârovâ D, et al. (2017) ) [Parathyroid cancer]. Vnitr Lek 63: 139-144.

9. Campennı A, Giovinazzo S, Pignata SA, Di Mauro F, Santoro D, (2017) Association of parathyroid carcinoma and thyroid disorders: A clinical review. Endocrine 56: 19-26.

10. Burmeister LA, Sandberg M, Carty SE, Watson CG. (1997) Thyroid carcinoma found at parathyroidectomy: association with primary, secondary, and tertiary hyperparathyroidism. Cancer 79: 1611-1616.

11. Zhao H, Zhao H, Wang C (2015) Bilateral papillary thyroid carcinoma concurrent with parathyroid adenoma: one case report. Lin Chung Er Bi Yan Hou Tou Jing Wai Ke Za Zhi 29: 565-566. 
Citation: Demir D, Çeler O, Arslan M, Durmaz H (2017) A Very Rare Case, Coexistence of Invasive Thyroid Papillary Carcinoma and Parathyroid Carcinoma in Hypercalcemic 29 Year Old Woman Who Is Treated For Urolithiasis. J Diabetes Metab Disord 4: 020.

- Page 3 of $3 \cdot$

12. Ming-Che Chang, Shih-Chuan Tsai, Wan-Yu Lin (2008) Dual-phase 99mtcmıbı Parathyroid Imaging Reveals Synchronous Parathyroid Adenoma and Papıllary Thyroıd Carcınoma: A Case Report. Kaohsiung J Med Sci 24: 542547.

13. Bosta B, Erdem M, Güne T, Șen C, Köseoğlu R.D, et al. (2010) Overlooked primary hyperparathyroidism presented with fractures: case report. Ulus Travma Acil Cerrahi Derg 16: 567-570.
14. Javadi H, Jallalat S, Farrokhi S, Semnani S, Mogharrabi M, et al. (2012) Concurrent papillary thyroid cancer and parathyroid adenoma as a rare condition: a case report. Nucl Med Rev Cent East Eur 15: 153-155.

15. Goldfarb M, O'Neal P, Shih JL, Hartzband P, Connolly J, et al. (2009) Synchronous parathyroid carcinoma, parathyroid adenoma, and papillary thyroid carcinoma in a patient with severe and longstanding hyperparathyroidism. Endocr pract 15: 463-468. 